\title{
CHARACTERS OF PHAGES FROM COAGULASE-NEGATIVE STAPHYLOCOCCI
}

\author{
J. Verhoef, C. P. A. van Boven and K. C. Winkler \\ Laboratory of Microbiology, State University, Catharijnesingel 59, \\ Utrecht, The Netherlands
}

\begin{abstract}
MANY strains of Staphylococcus epidermidis are lysogenic (Verhoef, van Boven and Winkler, 1971), and the phages isolated from them after induction with Mitomycin C fall into two groups: those that can be propagated on other strains of Staph. epidermidis and those that can be propagated on a nonlysogenic strain of Staph. aureus (no. 57), but not on Staph. epidermidis. We have studied the possibility that these phages might be used to type coagulasenegative staphylococci. Since Staph. epidermidis biotype 1 (Baird-Parker, 1965; syn. Staphylococcus subgroup II, Baird-Parker, 1963) forms the majority of the coagulase-negative staphylococci isolated from lesions (Holt, 1969; Verhoef, 1970) our work was mainly restricted to members of this biotype.
\end{abstract}

\section{MATERIALS AND METHODS}

The sources of the staphylococcal cultures used in this investigation, their classification into biotypes (Baird-Parker, 1965) and the methods used to detect lysogeny in them, have been described by Verhoef $e t$ al.

Phage-typing techniques. Phage-typing of the staphylococci with newly isolated phages was carried out by standard methods (Blair and Williams, 1961). In addition, the strains were typed by the same methods with the International Basic Set of typing phages for Staph. aureus.

Isolation and propagation of phages. Suitable dilutions of supernatant fluids that had lysed an indicator staphylococcus were streaked on plates flooded with the susceptible strain and incubated for $18 \mathrm{hr}$ at $30^{\circ} \mathrm{C}$. Phages were purified by picking a single plaque, which was spread on a new plate. After incubation, the area of lysis was scraped off and suspended in a small amount of broth. This was used to seed a broth culture of the sensitive strain. The propagated phages were centrifuged and titrated on the sensitive strain by spotting 10-fold serial dilutions of the supernatants. The crude phage suspensions that had a satisfactory titre- $1000 \times$ the routine test dilution (RTD) or more-were sterilised by filtration through membrane filters (grade $0.545,4.7 \mathrm{~cm}$ in diameter, Oxoid Ltd, London, England), checked for sterility and stored in $5 \mathrm{ml}$ vials at $4^{\circ} \mathrm{C}$. The phages derived from lysogenic strains were given the same number as the respective donor strain. Phage variants obtained by adaptation were designated by adding $\mathbf{A}$ or $\mathbf{B}$ to this number.

Phage adsorption. Bacterial suspensions containing about $10^{8}-10^{9}$ colony-forming units per $\mathrm{ml}$ were prepared by suspending the growth of agar slant cultures in $2 \mathrm{ml}$ broth; $0.5 \mathrm{ml}$ of phage suspensions containing on average $10^{7}$ plaque-forming units (p.f.u.) per $\mathrm{ml}$ were added, and the mixtures were subsequently incubated at $37^{\circ} \mathrm{C}$. Immediately after mixing and at intervals during incubation, samples were withdrawn and immediately diluted 100 -fold in broth. After centrifugation, further serial 10-fold dilutions were prepared, and the number of p.f.u. was assayed on a suitable indicator strain. Control experiments showed that when

Received 6 July 1970; accepted 17 Mar. 1971.

J. MED. MICROBIOL.-VOL. 4 (1971) 
phage suspensions were incubated in broth for similar periods of time the phage titre remained constant.

Phage-neutralisation test. Phage antisera were prepared in rabbits by the intraperitoneal injection of high-titre phage preparations ( $10^{9}$ p.f.u. per ml). Four injections of $1,2,5$ and $5 \mathrm{ml}$ respectively were given at intervals of 2 days followed by three injections each of $10 \mathrm{ml}$ at weekly intervals. The rabbits were bled 7-9 days after the last injection. The sera were absorbed with heated cells of Staph. epidermidis strain no. 407 before use, and were stored at $-20^{\circ} \mathrm{C}$.

The techniques used in the neutralisation experiments were based on those of Burnet (1933) and Rountree (1949). Serial 10-fold dilutions of the sera were prepared in broth. To $0.9 \mathrm{ml}$ of these dilutions, $0.1 \mathrm{ml}$ of phage suspension of about $10^{7}$ p.f.u. per ml was added. After incubation at $37^{\circ} \mathrm{C}, 0.03-\mathrm{ml}$ samples were withdrawn at specified intervals, and immediately diluted 100 -fold. Phage counts were made from suitable dilutions on appropriate

TABLE I

Lysis of Staph. epidermidis strains by 6 phages that had been propagated on strains of Staph. epidermidis

\begin{tabular}{|c|c|c|c|c|}
\hline \multirow{2}{*}{ Biotype } & \multirow{2}{*}{$\begin{array}{l}\text { Number of strains } \\
\text { examined }\end{array}$} & \multicolumn{3}{|c|}{$\begin{array}{l}\text { Number (and percentage) of strains of the stated biotype } \\
\text { lysed by one or more phages }\end{array}$} \\
\hline & & at RTD & at $\mathrm{RTD} \times 1000$ & Total \\
\hline $\begin{array}{l}1 \\
3 \\
4 \\
5\end{array}$ & $\begin{array}{l}63 \\
21 \\
39 \\
34\end{array}$ & $\begin{array}{r}19(30) \\
3(14) \\
7(18) \\
1 \quad(3)\end{array}$ & $\begin{array}{r}25(40) \\
3(14) \\
7(18) \\
0(0)\end{array}$ & $\begin{array}{r}44(70) \\
6(29) \\
14(36) \\
1(3)\end{array}$ \\
\hline All biotypes & 157 & $30(19)$ & $35(22)$ & $65(41)$ \\
\hline
\end{tabular}

indicator strains. The titre of the antisera against the homologous phages was expressed according to Adams (1959) as the neutralisation constant $\mathrm{K}$, determined over the first $5 \mathrm{~min}$. of neutralisation. Phages incubated with normal rabbit serum were not neutralised.

\section{RESULTS}

\section{Experiments with the first set of phages}

We selected 15 phages that had been obtained from strains of Staph. epidermidis-mainly from members of biotype 1 -in the course of the experiments described by Verhoef et al. in tables I and III of the preceding paper.

They were purified, propagated on suitable indicator strains and filtered; all the preparations had a strength of 1000 times the routine test dilution (RTD) or more. Six of the phages (no. 48, 51, 71, 82, 130 and 275), all derived from strains of biotype 1, were propagated on Staph. epidermidis strains and the remainder on the non-lysogenic strain of Staph. aureus no. 57 (Verhoef et al.).

Lytic activity on strains of Staph. epidermidis. The lytic action of the 15 phages was tested at RTD and RTD $\times 1000$ on a sample of 157 strains of Staph. epidermidis (table I). Sixty-five (41 per cent.) of them were lysed ( $>20$ plaques) by one or more of the six phages that had been propagated on Staph. epidermidis strains ( 30 at RTD and 35 at RTD $\times 1000)$ and a number of different patterns 
of lysis were observed. Members of biotype 1 were more often lysed than were members of the other biotypes. On the other hand, none of the strains was lysed by any of the phages that had been propagated on Staph. aureus no. 57, except phages no. 157 and no. 171, which gave a few plaques on Staph. epidermidis no. 382 and no. 368 respectively and were subsequently adapted to these strains.

Lytic activity on strains of Staph. aureus. To investigate the specificity of the phages for Staph. epidermidis, they were also tested in parallel with the

TABLE II

Lysis of 16 strains* of Staphylococcus aureus by Staph. epidermidis phages that had been propagated on Staph. aureus no. 57 and by the International Basic Set of phages

\begin{tabular}{|c|c|c|c|c|c|c|c|c|c|c|}
\hline \multirow{2}{*}{$\begin{array}{l}\text { Number of } \\
\text { staphylococcal } \\
\text { strain }\end{array}$} & \multicolumn{9}{|c|}{ Lysis $\dagger$ of the stated staphylococcus by phage } & \multirow{2}{*}{$\begin{array}{l}\text { Phage-typing pattern } \ddagger \\
\text { with the International } \\
\text { Basic Set of phages }\end{array}$} \\
\hline & 171 & 157 & 159 & 178 & 108 & 99 & 138 & 195 & 91 & \\
\hline $\begin{array}{r}22 \\
168 \\
9 \\
231 \\
21 \\
181 \\
125 \\
225 \\
180 \\
1 \\
104 \\
153 \\
160 \\
12 \\
227 \\
262\end{array}$ & $\begin{array}{l}\overline{+} \\
+ \\
+ \\
+ \\
+ \\
+ \\
+ \\
+ \\
+ \\
+ \\
+ \\
+ \\
+ \\
- \\
-\end{array}$ & $\begin{array}{l}+ \\
+ \\
+ \\
+ \\
+ \\
+ \\
+ \\
+ \\
+ \\
+ \\
+ \\
+ \\
+ \\
+ \\
+ \\
+\end{array}$ & $\begin{array}{l}+ \\
+ \\
+ \\
+ \\
+ \\
+ \\
+ \\
+ \\
+ \\
+ \\
+ \\
+ \\
+ \\
+ \\
+ \\
+\end{array}$ & $\begin{array}{l}+ \\
+ \\
+ \\
+ \\
+ \\
+ \\
+ \\
+ \\
+ \\
+ \\
+ \\
+ \\
+ \\
+ \\
+ \\
+ \\
+\end{array}$ & $\begin{array}{l}- \\
- \\
- \\
\overline{-} \\
- \\
\overline{-} \\
+ \\
+ \\
\pm \\
+ \\
+ \\
+ \\
+ \\
+ \\
+\end{array}$ & $\begin{array}{l}- \\
- \\
- \\
- \\
- \\
+ \\
\overline{+} \\
+ \\
+ \\
+ \\
+ \\
+ \\
+ \\
+ \\
+\end{array}$ & $\begin{array}{l}\overline{+} \\
\pm \\
- \\
= \\
= \\
\overline{-} \\
\overline{+} \\
+ \\
\overline{+} \\
+ \\
+ \\
+ \\
+ \\
+\end{array}$ & $\begin{array}{l}= \\
= \\
= \\
= \\
= \\
= \\
= \\
= \\
= \\
= \\
= \\
-\end{array}$ & $\begin{array}{l}\overline{-} \\
\overline{-} \\
\overline{-} \\
\overline{-} \\
\overline{-} \\
\overline{-} \\
\overline{-} \\
\overline{-} \\
\overline{-} \\
\overline{-} \\
=\end{array}$ & $\begin{array}{l}52 \\
52 \\
29 / 52 / 79 / 3 A / 77 / 83 A \\
52 \\
52 \mathrm{~A} / 81 \\
29 / 52(79 \mathrm{wk}) \\
81 / 3 A(7 / 54 / 77 / 83 A w k) \\
29 / 52 \\
52 / 81 \\
29 / 79 / 80 \\
29 / 79 / 80 \\
29 / 52(52 \mathrm{~A} / 79 / 80 / 81 \mathrm{wk}) \\
29 / 52 \mathrm{wk} \\
52 / 80 / 81 / 6 / 42 E \\
\text { NT } \\
\text { NT }\end{array}$ \\
\hline
\end{tabular}

* 15 other strains were not lysed by these Staph. epidermidis phages.

$++=\geqq 20$ plaques; $-=<20$ plaques. Phages used at a strength of RTD $\times 1$.

$\ddagger$ See Blair and Williams, 1961 . In italic: typing pattern at RTD $\times 1000$.

International Basic Set of phages on a batch of 31 cultures of Staph. aureus that had been isolated from patients and members of hospital staff. None of the Staph. epidermidis phages that had been propagated on Staph. epidermidis lysed any of the Staph. aureus strains, but seven of the nine Staph. epidermidis phages that had been propagated on Staph. aureus no. 57 lysed a number of the Staph. aureus strains, and gave a variety of patterns of lysis (table II). Over one-half of the Staph. aureus strains (16 of 31) were lysed by these phages. Most of the sensitive strains belonged to phage-group I in the Staph. aureus typing system; the strains that were resistant to these phages comprised three in phage-group II, two in phage-group III, three in phage-group IV and seven that were untypable by the Basic Set of phages.

These findings support our earlier suggestions (Verhoef et al.) that Staph. epidermidis strains carry two distinct groups of phages, of which one is active against Staph. epidermidis strains and the other against Staph. aureus strains. 


\section{Addition of a second set of phages}

A further collection of phages was examined. This series included the 15 phages mentioned in table II of the preceding paper (Verhoef et al.) and the induction lysates of six additional strains of biotype 1, which were active only on Staph. aureus no. 57. Phage 471, not mentioned before, was among the latter six. Eleven phages (five from the table mentioned and six additional phages) were propagated on Staph. aureus no. 57, and four (all mentioned in the table) were propagated on Staph. epidermidis no. 407. All these phages were tested, together with the six from the first set, on 20 strains of Staph. epidermidis. All the strains that were lysed by the newly isolated phages were also sensitive to one or more of the first set but, although the new phages did not increase the proportion of typable staphylococci, four of them (no. 108, 448,459 and 489 , all propagated on a single indicator strain, no. 407) were selected for further use because in a number of strains the lytic pattern could be differentiated by means of these phages.

The 11 phages propagated on Staph. aureus no. 57 again failed to give any significant lysis of the Staph. epidermidis strains, but two of them (no. 456 and 471) that gave very weak lysis on one strain each were used for adaptation in subsequent experiments.

\section{Adaptation of phages}

Because the induction of more phages did not increase the proportion of Staph. epidermidis strains that were typable, we attempted to adapt phages to the untypable strains. A number of staphylococci that gave weak reactions with certain of the Staph. epidermidis phages were flooded on plates and a drop of a concentrated preparation of the phage was superimposed. After incubation, single plaques were isolated, streaked on new plates, and then further propagated in broth. Titration of the centrifuged crude lysates on the new propagating strains indicated that in all cases a preparation with a strength of RTD $\times 100$ or more had been obtained.

In the first adaptation experiment, the six phages from the first set that had originally been propagated on Staph. epidermidis strains, together with two phages (no. 171 from the first set and no. 471 from the second set) that had originally been propagated on Staph. aureus no. 57, were adapted to one or several fresh strains of Staph. epidermidis (table III). The 16 crude lysates of the adapted phages obtained in this way were then tested for activity on 22 biotype-1 strains in parallel with the original phages; ten of these strains had been typable by the six original phages. Table III shows that eight more were typed with the adapted phages and four remained untypable. It will also be seen that the adaptation of the phages often resulted in a profound modification of the host range of the phages, including a loss of activity on staphylococci that had been susceptible to lysis by the unadapted phage.

As a result of these experiments, phage no. 71 propagated on strain no. 382, phage no. 82 propagated on strain no. 368 , phage no. 130 propagated on strain no. 141 , phage no. 275 propagated on strain no. 380 and phage no. 471 


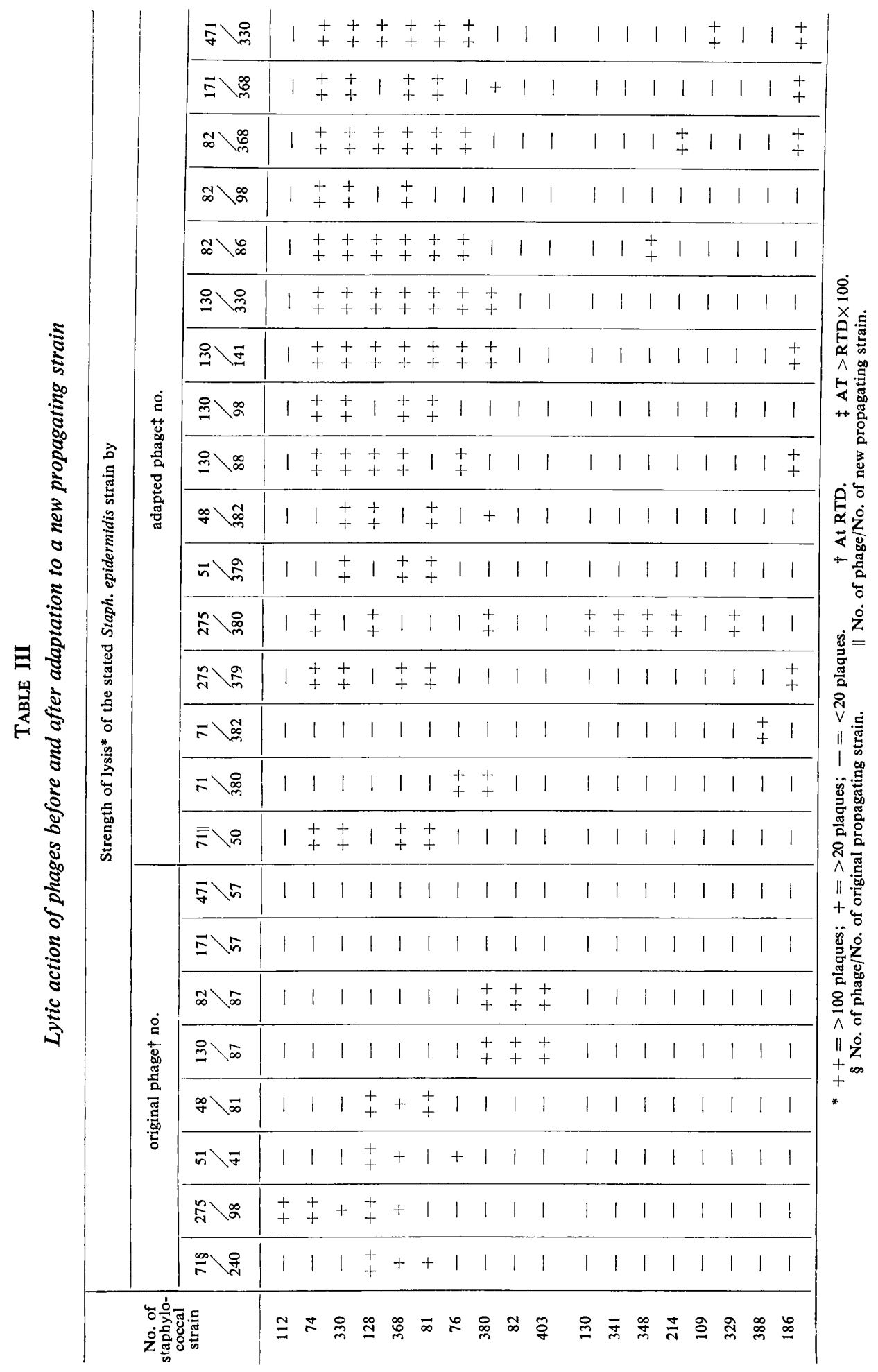


propagated on strain no. 330 were selected for further use and were designated as phages $71 \mathrm{~A}, 82 \mathrm{~A}, 130 \mathrm{~A}, 275 \mathrm{~A}$ and $471 \mathrm{~A}$ respectively.

In a second adaptation experiment, the results of which are not presented, three more adapted phages (no. 157 propagated on strain no. 382 , no. 275 propagated on strain no. 48 and no. 456 propagated on strain no. 76 ) were found to lyse several otherwise untypable strains of Staph. epidermidis, and were also added to the typing set under the numbers 157A, 275B and 456A respectively.

\section{TABLE IV}

Constitution of provisional set of typing phages for Staphylococcus epidermidis

\begin{tabular}{c|c|c}
\hline $\begin{array}{c}\text { Number of phage } \\
\text { and parent strain }\end{array}$ & $\begin{array}{c}\text { Original } \\
\text { propagating } \\
\text { strain }\end{array}$ & $\begin{array}{c}\text { Propagating } \\
\text { strain after } \\
\text { adaptation }\end{array}$ \\
\hline 48 & 81 & $\ldots$ \\
51 & 41 & $\ldots$ \\
71 & 240 & $\ldots$ \\
82 & 87 & $\ldots$ \\
130 & 87 & $\ldots$ \\
275 & 98 & $\ldots$ \\
$108^{*}$ & 407 & $\ldots$ \\
448 & 407 & $\ldots$ \\
459 & 407 & $\ldots$ \\
489 & 407 & 382 \\
$71 \mathrm{~A}$ & 240 & 368 \\
$82 \mathrm{~A}$ & 87 & 141 \\
$130 \mathrm{~A}$ & 87 & 382 \\
$157 \mathrm{~A} \dagger$ & $57^{*}$ & 380 \\
$275 \mathrm{~A}$ & 98 & 48 \\
$275 \mathrm{~B}$ & 98 & 76 \\
$456 \mathrm{~A}$ & $57^{*}$ & 330 \\
$471 \mathrm{~A}$ & $57^{*}$ & \\
\hline
\end{tabular}

With the exceptions indicated, all parental and propagating strains belong to biotype 1 .

* Staph. aureus.

$\dagger$ Staph. epidermidis biotype 4.

\section{Constitution of the provisional set of typing phages for}

Staphylococcus epidermidis

The provisional set of phages used for typing Staph. epidermidis strains is presented in table IV. The set is composed of the six phages isolated in the first series of induction experiments, four phages isolated in the second induction experiment and eight phages that had been adapted to new propagating strains. Three of the last had originally been propagated on Staph. aureus no. 57. A set of 23 Staph. epidermidis strains, comprising the 13 propagating strains and ten others, was chosen to characterise the host range of the phages of the provisional typing set. The relative strength of the reactions of the phages on these strains is shown in table $\mathrm{V}$, in which the phages are arranged in the order in which they are used in routine typing. 
PHAGES FROM STAPH. EPIDERMIDIS

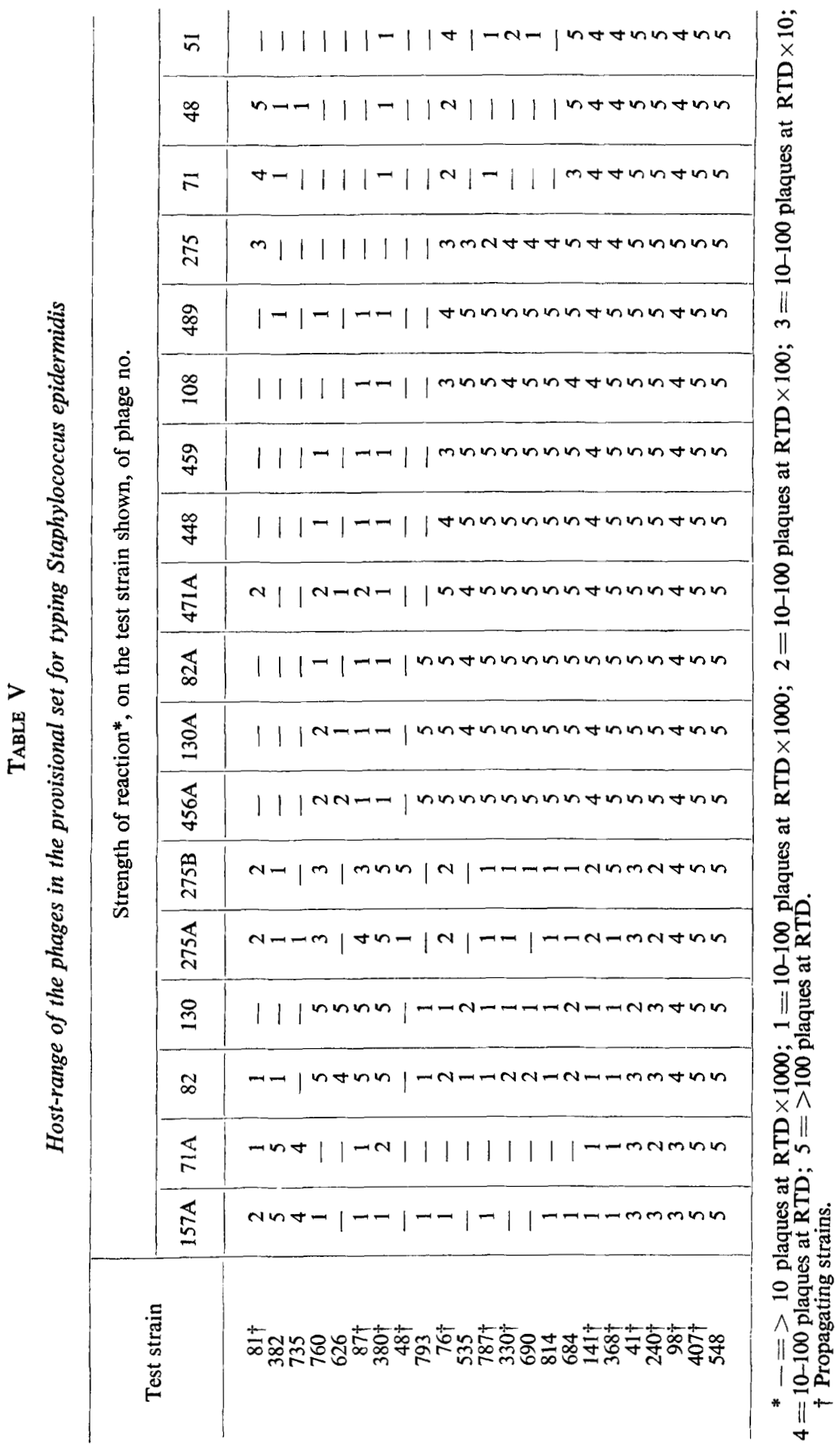




\section{Adsorption of phages}

Three phages, two isolated from biotype 1 (no. 71 and 82) and one from biotype 4 (no. 157A) were tested for adsorption on to the sensitive Staph. epidermidis strain no. 407 and on to the insusceptible Staph aureus strain no. 57. The curves in the figure show that the phages were not adsorbed by strain no. 57; even after incubation for $60 \mathrm{~min}$. no reduction in the number of p.f.u. was

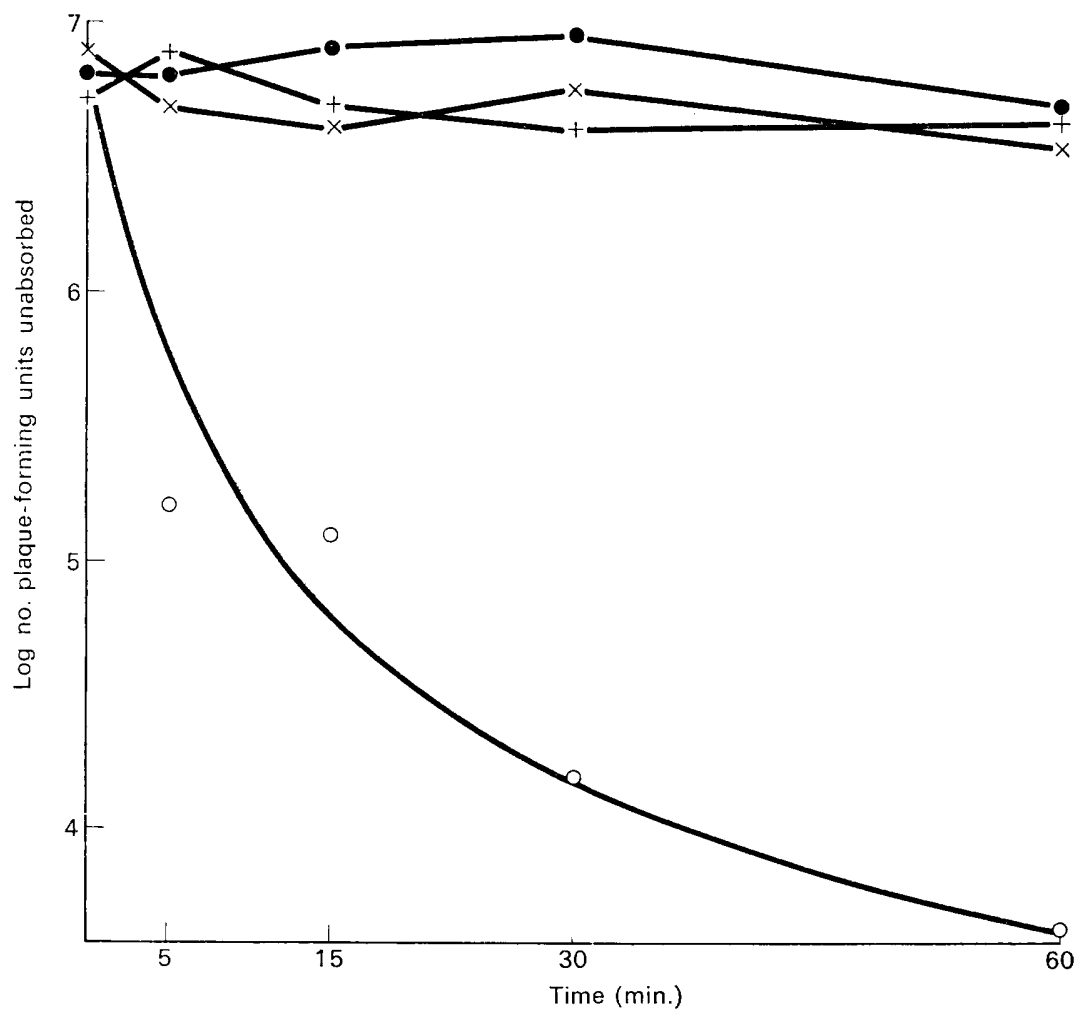

FIGURE.-Adsorption of Staphylococcus epidermidis phages by Staph. epidermidis and Staph. aureus. $\bigcirc-0$ phage no. 71 and Staph. epidermidis no. 407; $\bullet$ phage no. 71 and Staph. aureus no. $57 ; \times-\times$ phage no. 82 and Staph. aureus no. $57 ;+\longrightarrow+$ phage no. 157 and Staph. aureus no. 57. (For experimental details see Materials and methods.)

observed. In contrast, incubation of the phages with the sensitive strain no. 407, as illustrated by phage no 71 , led to a decrease in phage count by more than 90 per cent. in $5 \mathrm{~min}$., and a virtually complete inactivation after $60 \mathrm{~min}$.

In a later experiment, suspensions of the same three phages were incubated with the Staph. aureus propagating strains no. 3A, 42E and 187, and with four Staph. epidermidis strains of biotype 1 (no. 48, 87, 382 and 438) some of which were insusceptible to lysis by these three phages. Nevertheless, all of the Staph. epidermidis strains adsorbed the phages strongly within $30 \mathrm{~min}$. , but there was no decrease in the phage count in the mixtures containing the Staph. aureus strains. 
Fifteen other phages from the provisional typing set were tested for adsorption by Staph. epidermidis no. 407 and Staph. aureus no. 57. All were adsorbed by the former and none by the latter. For the phages no. 157A, 456A and 471A this is remarkable as they had been isolated and propagated on Staph. aureus no. 57 before the "adaptation" to Staph. epidermidis.

TABLE VI

Neutralisation of Staphylococcus epidermidis phages and of Staph. aureus phages by antisera prepared against Staph. epidermidis phages

\begin{tabular}{|c|c|c|c|c|c|c|c|}
\hline \multirow{2}{*}{\multicolumn{2}{|c|}{ Phage }} & \multicolumn{6}{|c|}{ Amount of neutralisation* of the stated phage by } \\
\hline & & \multicolumn{2}{|c|}{$\begin{array}{c}\text { phage-82 antiserum } \\
\text { diluted }\end{array}$} & \multicolumn{2}{|c|}{$\begin{array}{l}\text { phage-157A antiserum } \\
\text { diluted }\end{array}$} & \multicolumn{2}{|c|}{$\begin{array}{c}\text { phage-51 antiserum } \\
\text { diluted }\end{array}$} \\
\hline Origin & Number & 1 in 100 & 1 in 1000 & 1 in 100 & 1 in 1000 & 1 in 100 & 1 in 1000 \\
\hline Staph. epidermidis & $\begin{array}{c}71 \\
275 \\
48 \\
51 \\
82 \\
130 \\
456 \mathrm{~A} \\
157 \mathrm{~A} \\
471 \mathrm{~A}\end{array}$ & $\begin{array}{l}+ \\
+ \\
+ \\
+ \\
++ \\
++ \\
++ \\
++ \\
+\end{array}$ & $\begin{array}{l} \pm \\
\pm \\
\pm \\
\pm \\
+ \\
+ \\
+ \\
\pm \\
\pm\end{array}$ & $\begin{array}{l}+ \\
++ \\
++ \\
+ \\
++ \\
++ \\
++ \\
++ \\
++\end{array}$ & $\begin{array}{l} \pm \\
+ \\
\pm \\
\pm \\
\pm \\
+ \\
+ \\
+ \\
+\end{array}$ & $\begin{array}{l}+ \\
+ \\
+ \\
+ \\
+ \\
+ \\
++ \\
++ \\
++\end{array}$ & $\begin{array}{l} \pm \\
\pm \\
\pm \\
\pm \\
\pm \\
\pm \\
\pm \\
\pm \\
\pm\end{array}$ \\
\hline $\begin{array}{l}\text { Staph. aureus } \\
\text { (International Basic } \\
\text { Set) }\end{array}$ & $\begin{array}{r}29 \\
80 \\
6 \\
77 \\
187\end{array}$ & $\begin{array}{l}- \\
- \\
- \\
-\end{array}$ & $\begin{array}{l}- \\
\overline{-} \\
-\end{array}$ & $\begin{array}{l}- \\
- \\
- \\
-\end{array}$ & $\begin{array}{l}- \\
\overline{-} \\
-\end{array}$ & $\begin{array}{l}- \\
- \\
- \\
-\end{array}$ & $\begin{array}{l}- \\
- \\
- \\
-\end{array}$ \\
\hline
\end{tabular}

$*++=>99$ per cent.; $+=90-99$ per cent.; $\pm=25-90$ per cent.; $-=<25$ per cent.

\section{Phage-neutralisation tests}

Three of the Staph. epidermidis phages, no. 51, 82 and 157A, were sent to Dr Elizabeth H. Asheshov at the Central Public Health Laboratory (Colindale, London, England) for serological studies. She reported that none of the available antisera against phages of coagulase-positive staphylococci neutralised the phages.

Subsequently, rabbits were immunised with these three phages, and the antisera examined for neutralisation of Staph. aureus and Staph. epidermidis phages (see Materials and methods). The neutralising activity of the antisera against the homologous phages, expressed as the neutralisation constant $\mathrm{K}$ was 24 for phage 51 antiserum, 41 for phage no. 82 antiserum and 45 for phage no. 157A antiserum. Table VI shows the neutralising capacity of the antisera diluted $10^{-2}$ and $10^{-3}$ expressed as the percentage neutralisation after $30 \mathrm{~min}$. at $37^{\circ} \mathrm{C}$, against nine phages derived from biotype-1 and biotype- 4 Staph . 
epidermidis strains, and five Staph. aureus phages from different serological groups (phage no. 29 and 80, group B; phage no. 6, group A; phage no. 77, group F; phage no. 187, group L). The latter phages were not neutralised by the antisera to any significant degree. The Staph. epidermidis phages, although small differences were observed, were all neutralised to over 90 per cent. by the three antisera. These results are in agreement with those obtained with the antisera against the phages of coagulase-positive staphylococci. They indicate that the phages against strains of biotype 1 and biotype 4 of Staph. epidermidis form a homogeneous serological group, distinct from the Staph. aureus phages. It is noteworthy that the Staph. epidermidis phages tested included three that had originally been propagated on Staph. aureus no. 57.

\section{Discussion}

A provisional set of 18 phages for typing Staph. epidermidis of biotype 1, was obtained by induction of Staph. epidermidis and by adaptation. The history of these phages was various (table IV). Nine were obtained by induction of strains of biotype 1; five of these underwent a change of host range on adaptation. Three other phages which after induction were active only on Staph. aureus no. 57 could be adapted to Staph. epidermidis. One phage was derived from a Staph. aureus (no. 108). All these phages were propagated on Staph. epidermidis strains of biotype 1 .

Notwithstanding these differences in history, all the phages had several characters in common and formed a distinct group. They were all adsorbed to other Staph. epidermidis strains even when a strain was insusceptible to such a phage. They were, however, not adsorbed on to Staph. aureus strains including strain no. 57. The phages from Staph. epidermidis strains that were initially propagated on Staph. aureus no. 57 also lysed a number of other Staph. aureus strains, but did not lyse Staph. epidermidis strains to any significant degree. Some of them could, however, be adapted to lyse Staph. epidermidis strains, and after adaptation they were also adsorbed on to Staph. epidermidis strains but not on to Staph. aureus no. 57.

Antisera against Staph. aureus phages of groups A, B, F and L did not neutralise Staph. epidermidis phages that had been propagated on strains of the same species. On the other hand, antisera prepared against three Staph. epidermidis phages of the same class neutralised all the Staph.epidermidis phages that were tested, including three that had originally been propagated on Staph. aureus no. 57 and later adapted to lyse Staph. epidermidis strains. These sera did not neutralise any of a series of Staph. aureus phages.

The Staph. epidermidis phages that initially lysed other Staph. epidermidis strains therefore formed a class quite distinct from the temperate phages of Staph. aureus. The behavoiur of the three Staph. epidermidis phages that initially lysed only Staph. aureus strains is peculiar. Their host-range on initial isolation suggests that they might belong to the different class of phages that lyses only Staph. aureus (table II), but this conclusion is not supported by their serology or their behaviour in adsorption experiments. Further study is 
required. As the cause might be different in each case some experiences are mentioned here. Phage no. 489 propagated from what seemed a single plaque on Staph. epidermidis no. 407 was active on the propagating strain and on Staph. aureus no. 57. It proved to be an equal mixture of two phages from which the present phage no. 489 (not active against Staph. aureus no. 57) was isolated. As neither Staph. aureus no. 57 nor Staph. epidermidis no. 407 could be shown to carry a lysogenic phage, both phages must have multiplied on Staph. epidermidis no. 407 . We suggest that the induction lysate contained two phages and phenotypic mixtures, that double infection with phage 1 and the adsorbing phenotypic mixture with genome 2 occurred in the plaque as well as during propagation and permitted the propagation. An analogous explanation might apply to some of the three cases under discussion.

Again, phage no. 157, propagated from a single plaque on Staph. aureus no. 57, was not neutralised by the antiserum against phage $157 \mathrm{~A}$. It did adsorb to the propagating strain, but not significantly to Staph. epidermidis no. 382, though a few plaques were observed. Whether the adaptation selected a contaminating phage, a mutant affecting host range and serology, or a minority phage derived from strain 157 and propagated through strain 57 with the help of phenotypic mixtures, remains in doubt.

Serological differences exist between these Staph. epidermidis phages and the phages active against Staph. aureus. This is in agreement with the results of Rountree (1949) and Rippon (1956) and might be related to the difference in phage receptor on the surface of the two species of Staphylococcus. Ralston (1963) and Chatterjee (1969) concluded that the receptor material forms part of the teichoic acid in the cell wall, which is different for Staph. aureus and Staph. epidermidis (Baddiley, 1968).

Further work will be necessary to determine the value in epidemiological studies of typing with the provisional set of Staph. epidermidis phages.

\section{SUMMARY}

Further study of the phages isolated from lysogenic strains of Staphylococcus epidermidis confirms that they are of at least two classes: (1) phages active only on other Staph. epidermidis strains and (2) phages initially active only on Staph. aureus strains but sometimes adaptable to lyse Staph. epidermidis strains. Ten phages of the first class, five adapted phages of the first class and three adapted phages of the second class could all be propagated on strains of Staph. epidermidis of biotype 1. They are all adsorbed by strains of Staph. epidermidis and belong to a single serological group that is distinct from the groups A, B, F and L of Staph. aureus phages.

A provisional set of 18 phages proposed for typing Staph. epidermidis is described and characterised.

In addition to the colleagues whose contributions were acknowledged in our earlier publication (Verhoef et al., 1971) we wish to thank Dr Elizabeth H. Asheshov for the serological characterisation of some phages. 


\section{REFERENCES}

AdAMs, M. H. 1959. Bacteriophages, New York.

BADDILEY, J. 1968. Teichoic acids and the molecular structure of bacterial walls. Proc. Roy. Soc. B, 170, 331.

BaIRD-PARKeR, A. C. 1963. A classification of micrococci and staphylococci based on physiological and biochemical tests. J. Gen. Microbiol., 30, 409.

BaIrd-Parker, A. C. 1965. Staphylococci and their classification. Ann. N.Y. Acad. Sci., 128, 4.

Blair, J. E., AND Williams, R. E. O. 1961. Phage typing of staphylococci. Bull. Wld Hlth Org., 24, 771.

BURNET, F. M. 1933. The classification of dysentery-coli bacteriophages. II. The serological classification of coli-dysentery phages. J. Path. Bact., 36, 307.

ChATtERJEe, A. N. 1969. Use of bacteriophage-resistant mutants to study the nature of the bacteriophage receptor site of Staphylococcus aureus. J. Bact., 98, 519.

HoLT, R. J. 1969. The classification of staphylococci from colonized ventriculo-atrial shunts. J. Clin. Path., 22, 475.

RaLSTON, Doris J. 1963. Staphylococcal sensitization: specific biological effects of phage K on the bacterial cell wall in lysis-from-without. J. Bact., 85, 1185.

RIPPON, JOAN E. 1956. The classification of bacteriophages lysing staphylococci. J. Hyg., Camb., 54, 213.

Rountree, Phyllis M. 1949. The serological differentiation of staphylococcal bacteriophages. J. Gen. Microbiol., 3, 164.

VERHOEF, J. 1970. Fagotypering van coagulase-negatieve stafylococcen. M.D. Thesis, Univ. Utrecht.

Verhoef, J., van Boven, C. P. A., AND WinkleR, K. C. 1971. Lysogeny in coagulasenegative staphylococci. J. Med. Microbiol., 4, 405. 